\title{
Contending with Governance and Leadership as Critical Issues within the Maltese Educational System
}

\author{
Christopher Bezzina* and Mario Cutajar
}

Department of Education Studies, Faculty of Education, University of Malta, Msida MSD 2080, Malta

\begin{abstract}
In a context of reform aimed at providing a quality education for all children, governance and leadership play a crucial and central role. Hence, it has been deemed essential to study the way governance and leadership are being tackled and introduced by central authorities as they move towards greater devolution of authority to the micro level, represented in Malta through a College network system. The article takes cognisance of the fact that we are still in the initial stages of the reform and that the reflections are based on initial studies that have been carried out over the past few years and a critique presented by the authors. Striking the balance between centralized and decentralized practices, focusing on different forms of professional development, a heavy emphasis on co-operation and sharing of good practices have been identified as essential ingredients that have to be addressed in a strategic manner and sustained over time.
\end{abstract}

Keywords: Centralisation, decentralisation, educational reform, governance, leadership, Malta.

\section{INTRODUCTION}

This article explores the evolving nature of governance and governing within the Maltese educational system. It presents the desired move from a centralized system to a decentralized one by exploring a number of leadership challenges that it brings with it at the organizational and human levels. A full understanding of educational governance in general and school governance in particular provides a fundamental starting point to the understanding of governance processes in the educational sector. Despite the absence of a single, agreed view on what governance means and embraces, the concept is gaining widespread currency [1].

\section{EDUCATIONAL GOVERNANCE - RAISON D'ETRE}

The currency of the term 'governance' has brought on innumerable definitions each depending on the context and the need, and consequently there appears to be no single, accepted definition. Rhodes [2] has in fact identified six distinct uses of the term. James et al. [1, p.10] attempt to give a generic description as to what governance is concerned with by contending that: "Governance in a general sense refers to the 'patterns of rule' which are concerned with regulation, direction and procedure."

Macnamara defines governance as:

'the combination of policies, systems, structures and a strategic/operational framework; which the governing body puts in place to ensure the leadership of the organization makes appropriate decisions, and takes appropriate actions to deliver services in an effective and accountable manner.' [3, p. 1]

\footnotetext{
*Address correspondence to this author at the Department of Education Studies, Faculty of Education, University of Malta, Msida MSD 2080, Malta; Tel: +356 2340 2039; E-mail: christopher.bezzina@um.edu.mt
}

On the other hand Ranson [4] identifies governance in terms of structured control and conformity; Stoker [5], looks at governance from the lens of governing body or council that takes decisions and action collectively, and Ackerman [6] recognises it as a body that takes responsibility and is accountable to a number of stakeholders.

This variability is illustrated further by the European Commission's view of governance where they state that: "...the term governance is a very versatile one. ... it is an allembracing concept capable of conveying diverse meanings, ... and referring to the exercise of power overall ..." [7]

Taking into account the diverse keywords such as 'educational quality assurance', 'quality management', 'educational performance management' and 'educational management' that relate to governance, together with the wide range of players involved or have a vested interest in school governance, it comes as no surprise to read that "a large part of governance is managing for and being accountable to a variety of stakeholders" [8, 9, p.73]. Another study by Lawn \& Ozga [10] present assessment results as a characteristic of governance in education. Additionally, Cowie and Cisneros-Cohernour [11] establish a link between performance management, accountability and educational governance. They argue that schools and governing boards have been accrediting importance to funding and rating. They continue to add that this is rather worrying because it has prompted the demand for a more professional approach to accountability which in turn has given assessment results such a predominant place in the education policy of a number of countries, that assessment results "may now be understood as a form of governance in education" $[10$, p. 1$]$.

However, one is inclined to ask: is educational and school governance just about managing and accountability? If anything, is it that clear-cut? Considering, the nature of human dynamics coupled with the responsibilities which society has bestowed upon schools in the formation of good 
citizens, together with the fact that schools are being collocated to form educational networks and also the various members involved in school governance and its organizational structure it comes as no surprise that educational and school system of governance, in which each party or individual plays a unique role, is complicated [2] and contested [12]. This challenging factor is alluded to again by James et al. [1] in their article on how school governing bodies function in diverse socio-economic and school performance settings. They state that there is "a complex interplay between school governing, socioeconomic context and school performance" (p. 415). This continues to demonstrate that governance, particularly school governance is not that clear-cut but rather intricate; more so, when considering what Macnamara argued about 'good governance': "Today and into the future, the standards for what makes 'good governance' are rising, and demanding more time and attention... There is much more to good governance than simply adopting a particular model of governance" $[3$, p. 1].

O’Neill [13], whilst arguing for a change in the existing culture of accountability contends that "good governance is possible only if institutions are allowed some margin for self-governance of a form appropriate to their particular tasks...". In her contention, O’Neill speaks for less central control.

Undoubtedly we are witnessing one of the most engaging periods of reform ever experienced in Malta. The Amended Education Act (2006) presents us with the shift in decision making that saw its inception a decade before, in the mid $1990 \mathrm{~s}$, as the government sought to respond to the need to adopt a more distributed style of decision making. Reculturing and restructuring [14] are at the heart of the reform that we are presenting in this article. It aims to highlight some of the critical factors and findings as Malta has embarked on a system of devolving greater responsibilities to the school site. This is being achieved through a system of inter-school networking of all State primary and secondary schools (similar to federations in the United Kingdom). Whilst this is identified as a potentially effective way forward to help us address the needs of the child to face present and future challenges, we also raise concern that the process in itself needs to be constantly engaged with, as new challenges and issues surface, as people learn to engage in new and diverse ways [15].

In the next section we present the contextual scenario to the Education (Amendment) Act 2006. We then develop the leadership challenges that the law provoked and address some of the recent studies on the implications of governance and governing.

\section{THE CONTEXT}

The context is definitely crucial to our understanding of governance and how it can unfold and affect policy making and implementation. Focusing on contemporary education reforms, particularly those addressing decentralisation and school autonomy, one observes that school governance has gained a diverse spectrum of parties with particular responsibilities because of the concept of empowered and shared decision-making at school level [16]. Consequently, considering the interrelationship and diverse interest of the different parties involved in the educational journey of the child, school governance can be said to be somewhat of a problematic concept that involves both formal and less formal controls and influences over schools [3]. This state of affairs may have developed because the remit of the various parties with management responsibilities and their respective boundaries of governance within the school or college have very often been left undefined and vague. Perhaps the way forward is to perceive school governance as a network. James et al. [1] underlined the perception of governance as a network when they maintained that "the conceptualization of school governance as a network is valuable" (p. 394).

Within a College network system one can find an intricate system of rule that has come to be known as sitebased management (SBM) [17]. SBM has been defined by Gaziel [18, p. 20] as the "...delegation of authority to individual schools, a model of shared decision-making involving various stakeholders, and facilitative leadership at the school level." This managerial pattern can involve a number of groups or individuals with assigned responsibilities, for example, board of governors, school councils, principals, headmasters, teachers and student councils.

However, because of the wide range of players involved in school governance, their extensive responsibilities [18], and because of the "continual and dynamic interactions of network actors, and shifts in the rules ... governance networks are in a continual state of flux [19, 1, p.394]. James et al. highlight the need for a reflective and analytical exercise of school governance as a network to try and overcome complexities that may arise. They contend that the "conceptualisation of school governance as a network is valuable but it calls for an analytic framework for understanding: the 'location' of actors in the network; and what guides and forms their actions and their modes of working" [20, p.394].

\section{SCHOOL GOVERNANCE}

Ranson [4], argues that "governance matters because: it strengthens the practices which secure institutional performance; it mediates the social and cultural conditions that engage young people in their learning; and it constitutes the practices of engagement, participation and deliberation which secure that mediation" [4, p. 411].

Riley and MacBeath [21] among other issues, present a review on the debate on the notions of 'good' and 'effective' schools. In their claim, which seems to place schools as essential to society and its political milieu, they acknowledge that:

\footnotetext{
'The notion of a good school is a social construct, shaped by national expectations and local aspirations. Equally, the notion of an effective school is socially constructed. Both notions rest on a belief that schools can make a difference...' (p.176)
}

The interest in school governance among researchers is growing [1, 22-24], particularly owing to the impact that schools can have on individuals. Schools have gained significance because: 
- $\quad$ they are at the heart of all education systems

- they lay the foundations for future societies

- $\quad$ they play a crucial role in forming good citizens [4]

- $\quad$ and they have "...the demanding and vital role of developing the potential of children and young people" [25, p. viii]

The possible reason why school governance has continued to gain mileage in research and in the educational sector is twofold. First, the shift towards greater democratic participation in schools. Second, with accountability for achieving set targets becoming the rule of the day all stakeholders are responsible for particular roles they are being called to fulfil to ensure that their schools and colleges not only provide and sustain good quality education but ensure that students get their entitlement and achieve the milestones that can take them into adult life $[17,18]$.

Modern societal culture has fostered the need of a new framework for school governance, especially when one reflects well on some of the conclusions reached by Ranson

- 'that the purpose of governance is to develop the public goods of learning and citizenship' [4, p.411]

- and accordingly, 'a public education ... is the responsibility of the community and civil society as a whole' [4, p.411].

James et al. reinforced the importance of a renewed structure for school governance when they contended that although schools needed governing bodies and the system worked, on the whole there was room for improvement and "...it will need to change if it is to respond to the ways schools are changing" [1, p.4]. In this regard, the literature $[16,20,26]$ has demonstrated that the practice of governance seems to be improving because governing bodies are taking an active, often strategic role since performance monitoring is becoming a key function of any governing body.

James et al., in discussing the issue of school governance, introduced the notion of "governance capital" [20, p.429], which they define as "the network of individuals and their capabilities, relationships and motivations that are available for the governance of any particular school" (p.429). They [20] established a relationship between school performance and the level of the members of the school governing board. They recognised that the members of governing boards can have a diverse mix and changes over time. Consequently, they assert that "...a school's governance capital can be built and needs to be. Further, it will need to be drawn upon continuously in a range of ways because of the turnover of governors resulting from their limited period of tenure" [20, p.429].

Within such a context one has to be cautious as to how school governing bodies are constituted and function because they can be both a strength and a weakness, given the potential lack of stability and continuity.

\section{A HISTORICAL OVERVIEW}

An overview of noteworthy landmarks in the development of the Maltese education system, particularly those between 1988 and 2005, will help to give depth and scale to this section of this article. It will also place in perspective the conceptual framework which is exploring the evolving nature of governance and governing within the Maltese educational system. In understanding the early stages of the Education (Amendment) Act, 2006 reform, it is important to point out that the existing state-maintained clusters of primary and secondary schools, which between 2005 and 2007 were known as 'School Networks', are presently identified as Colleges. The Maltese State schools have been clustered into ten Colleges brought together on a regional basis.

The historical development of Maltese education shows that the ultimate objective behind the implementation of Maltese educational reforms was to augment the country's intellectual capital and this has always been a priority for the Maltese Government.

The several major educational reforms that have been implemented throughout the years, especially those after September 1964 when Malta gained its independence, continue to underline the mission of the Maltese Government to provide the necessary education and training in areas that address the Maltese economy.

The educational reform, Education Act (Act XXIV of 1988) [27] is built on a set of Principles primarily that the students' holistic well being should be at the centre of each education activity, education programme provided within the state and non-state (Church \& Independent) systems, and each and every student should be provided with:

a. Educational programmes that cater for their individual educational needs;

b. Educational programmes that, first and foremost, identify the abilities, the potential and the challenges that each and every student is facing; and

c. Design programmes that cater for such potential and such abilities.

Before the 1990s, the operations of State-maintained schools in Malta were largely dependent on policies emanating from central authorities - the former Education Division. The constitution of school networks in 2006 required a shift towards a decentralized system. As documented by Fenech [28], the road to this new form of educational democratization finds its origin, as early as 1989 , in a number of Ministerial pronouncements on the introduction of the decentralization theme in educational policy.

In 1989-1990 the Minister of Education set the wheels in motion for the eventuality of the decentralisation of the Maltese Education system so that schools could be better empowered. In 1994 a Consultative Committee on Education [29] whose remit was to re-examine and revise educational policies and practices, published its report: Tomorrow's Schools: Developing Effective Learning Cultures. This document proposed the development of schools as learning communities which were to cater for the well-being of students, and which were to bring together the experience and expertise of teachers and parents for the benefit of the educational needs of the students. A significant educational landmark which followed the presentation of this report was the National Minimum Curriculum (NMC) document presented by the Ministry of Education in 1999. The NMC 
laid down the kind of educational knowledge and skills that a child needed to acquire, and to grow up valuing democracy and solidarity. On a general note, the NMC gives substance to the concepts of collegiality, consultation, partnership and collaboration among students, educators and stakeholders within the parameters of the networking policy, as outlined in the NMC Strategic Plan [30]. The NMC of 1999 called for radical changes in the whole culture of philosophical and pedagogical practices.

The networking policy, which has its roots as early as 1999, reached its realization in 2005, when the same Ministry launched the networking reform policy document For All Children to Succeed: A New Network Organization for Quality Education in Malta [31]. This revolutionary seminal document provided proposals for an overhaul of the Maltese Education system that was meant to bring about a paradigm shift in local education. The whole notion was not to introduce a new model but to improve the existing one. Reengineering is a conceptual framework which Hammer and Stanton defined as "the fundamental rethinking and radical redesign of business processes to bring about dramatic improvements in performance" [32, p.3]. Reorganizing and modifying the existent model required schools to work in partnership, share resources, jointly solve problems and create new practices so that no child would be left behind. The adjustment was to establish a strong orientation towards a collaborative mindset that was meant to consolidate an effective collegial spirit. This was aimed at transforming the existing practice of teachers working mostly in isolation. Maltese state-maintained schools had for years worked in isolation as independent units and inculcated a culture that had led to teachers entrenching themselves in set ways and preferring to work on their own $[33,34]$. It is within this context that the cultural change underlining the significance of team work and joint working has to take place.

Looking at all the different measures that encompass this reform it becomes evident, especially to educators that while we need to change the system as quickly, as efficiently and as effectively as possible, one has to be careful against a 'big bang' approach. In the past there were the 'big bang' approaches and these approaches have shown that they have a negative impact not only on the student but also on the teaching community. The philosophy behind the present reform is evolution and not revolution.

In 2006, the proposed policies of networking that were presented in the document For All Children to Succeed [31] aimed at bringing fundamental changes in the way school and college practitioners synergize, relate and collaborate were endorsed in the Education (Amendment) Act, 2006 [35]. Both official documents could be regarded as the precursors of reforms that were set in motion in 2006, and which are still ongoing. These reforms have brought with them a paradigm shift for the Maltese Education System and the professional practice of its stakeholders. The reforms were expected to challenge the mindset of all the stakeholders, particularly of those who are prone to resist change. They introduced challenges that the professional corpus of educators and other stakeholders would need to contend with and override if Maltese Education is to move from strength to strength.
The reform advocated a change in educational governance, from a 'top-down' bureaucracy to 'communities' where parents and practitioners, who work within them, come together for the benefit of the learning child. Its suggested systemic transformation, which entailed a paradigm shift in mindset and culture, became a working reality by the endorsed policies in the Education (Amendment) Act, 2006.

Educational Maltese policy makers saw the growing move towards the establishment of networks, clusters or federations abroad as the way forward to enhance the quality of education, whilst at the same time acknowledging that there is no blueprint for an effective network [36]. They recognized that the organization of networks in education is an almost worldwide phenomenon: "There are now many schools, both in the U.K. and internationally, that benefit from working together as a network" $(31$, p. 38). Networking was going to be a ground-breaking experience for Maltese state schools and consequently, any form of change would not be easy. It was bound to create a national debate, cause a certain degree of discord and generate tension and challenges among the school practitioners as they adjusted to changing individual circumstances: "The task ahead is a mammoth one. It will involve collective commitment, discipline and effective network leadership" (31, p. xxi). Convincing Maltese professional educators with years of experience, who felt and thought that they had been working within a conservative yet successful education system; to endorse the reform and adopt the proposed change as the way forward could be testing. In effect, the transformation of the Maltese education system into a new framework provoked a vigorous and ongoing debate among a diverse mix of participants (the Ministry of Education, University academics, the Malta Union of Teachers, and stakeholders, - teachers, Heads of school and school network coordinators). For the sake of accuracy, it is important, at this point, to mention that in 2005 leaders of school networks were known as Coordinators. In 2008 they came to be known as 'College Principals' as sanctioned by The Act of 2006.

It was widely acknowledged that the traditional school system was no longer appropriate to take Maltese education into the $21^{\text {st }}$ Century and it had become clear that a change was essential [31]. The then Minister of Education stated that:

New educational research and the far reaching technological developments changing the world around us, however, make it clear the education system as we know it has reached its limits. It urgently needs renewal to remain relevant (31, p.: xi)

This statement emphasises the necessity of reforming a conservative and outdated model to bring it in line with current developments.

The determined move to devolve greater responsibilities to the College site, sees College Principals, through their respective Council of Heads, taking quite a lot of the decisions that will determine the ethos and culture of each College. Up to this stage of the reform, and as stipulated by the Education Act [35], policy direction will still come from the centre through two Directorates who will introduce 
various policy initiatives. Such direction, although adopting a collaborative and broad consultative style is, in our opinion, especially necessary in this stage of the reform process. One of the major challenges that faces the reform is how to develop a balanced approach to decision making as one shifts from a highly centralized system to a more democratic and participative model.

With distributed leadership being proposed as a response to the challenges facing our country it will be interesting to see what types of power struggles ensue as we try to move away from the character and structures of institutions that adopted a top-down, hierarchical, managerial approach to decision making and decision taking. With this backdrop we now move to the challenges we feel educators at all levels will have to contend with.

\section{THE LEADERSHIP CHALLENGES}

The Education Act [35] proposes a system that serves the end of enhanced achievement for all students. The Act proposes a shift from a 'top-down' model of administration to one where meaningful growth can come from a concerted effort to focus on change from a dual perspective - 'inside out' and 'outside in', what can be described as a systemwide reform. The drive is to create a model of learning that permeates the whole system.

Such a move requires several significant shifts - from unconnected thinking to systems thinking, from an environment of isolation to one of collegiality, from perceived reality to information-driven reality, and from individual autonomy to collective autonomy and collective accountability. The school as a competent system has a shared vision that articulates a coherent picture of what the school will look like when its core beliefs are put into practice. It collects and synthesizes information on student achievement, identifies the gaps between current and desired performance, explores research and best practices to identify possible strategies or frameworks to enhance teacher practice, and then chooses an innovation or a bundled set of innovations to close the gap between where the school is and where it has to be to fulfil its vision. It has a staff development programme and a related action plan that are necessary if the school is to achieve its shared vision. In the process of building a competent system staff members emerge as a professional learning community, embracing collective accountability as the only way to achieve the shared vision for all students [14].

Naturally, such a drive takes time and we cannot expect the reform to have its desired impact on all at the same time. Reform takes place at an "excruciating slow pace" notes Fullan [37, p. 302]. We have to remain patient and persevere in our drive. The next section explores a number of what we are describing as leadership challenges that the reform is presenting us with.

\section{Leadership is Relationships}

There are a number of challenges that the reform that we are currently engaged in presents us with. The first lesson we want to share is that leadership is about relationships. Thomas Hoerr argues that "good leaders change organizations; great leaders change people. People are at the heart of any organization, particularly a school, and it is only through changing people - nurturing and challenging them, helping them grow and develop, creating a culture in which they all learn - that an organization can flourish" [38, p.7]. Local research [39] shows how our College Principals are at different stages of development as they move across the progressive cultural phases from the dominant ' $I$ ' to the 'We' culture. Maltese College Principals and Heads are moving from the industrial, scientific management model to the distributed models of leadership. However, not without difficulty. A study that recently explored the impact of the College Principal on heads of school has shown that healthy relationships are at the basis of any successful organization. They also note that the personality and values of the College Principal are determining the type of relationships being fostered and leaving an impact at other levels [40, 41].

This is an area at the heart of governance. Moving from a top-down approach to change to more distributed forms of power has to be carefully monitored as in reality what may happen is a shift from one form of control to another, hence moving the existing system of command and direction from central authorities to another level. Some evidence shows that this is a concern to be contended with [41].

\section{Devolving Responsibilities}

Leaders increase a group's productivity by helping everyone in the group to become more effective. Whatever the task or goal a leader helps everyone to improve. A leader begins by setting the vision, and does so by listening, understanding, motivating and incorporating others' ideas and talents and energies into forging the vision [42]. In the College network context we are seeing College Principals who are highly visible, visiting schools and classrooms regularly so that they know what is going on. A number of studies are showing that College Principals are engaging their staff in decision making through a culture of collaboration [43, 44]. Another study [45] has identified that the reform has encouraged and empowered inter-school collaboration.

Leadership is all about being inclusive. Fabri and Bezzina [14] help us to appreciate that leadership happens at many levels and comes from many individuals. We are no longer talking of Directors giving direction from head office, or the school Head who takes decisions from 'on high'. We are witnessing College Principals whose brief calls them to be invitational [44]. A number of studies show that through their position they are creating opportunities for shared and distributed leadership [40, 45].

It is through systems thinking and collegial conversation that administrators and teachers begin the process of critically analyzing assumptions that perpetuate the status quo, recognising previously unseen complexities and conflicts within the school, welcoming problems as challenges, and perceiving the gaps between what is and what can be. For the school to have purpose, members of the school community must identify their core beliefs and develop a shared vision.

In his book Improving schools from within [46] Roland Barth maintains that collegiality is the most important factor in determining the success of a school. The promise of collegiality is simple yet powerful: if students are to grow and learn, the adults in the school must grow and learn too. 
When a school is alive with collegiality, then creativity and passion thrive, and teachers actively engage in improvement activities [47]. Good leaders truly bring out the best in others. Collegial relations and collective learning are at the core of building the capacity for school improvement. Whilst local research has not been conclusive one notes that as attempts are made to break the isolationist mentality we were used to [36] by nurturing contexts based on communication, active engagement, motivation and commitment, we are witnessing new challenges - often of a territorial nature, of power struggle.

\section{Shared Leadership}

To foster lasting and meaningful change we are witnessing a greater and more direct involvement of all educators. In such a context leaders are not always at the centre of every initiative. It helps us to appreciate that good leaders are always in the quest of improving and are not scared of other people knowing more than they do. Teacher leadership connects teachers and the Senior Management Teams in their mutual mission: improving learning for students [43]. The local examples help us to appreciate the observation made by Houston that "the role of an educational leader is to build a bridge and lead people across it, because it is only by crossing that bridge that people can find a new place to stand" [48, p.2].

The job of the Principal is to create a school culture that transcends personality, even his/her own. A strong culture offers a clear sense of expectations to everyone about what is important. This includes how to teach students, as well as how to interact with other adults. In talking about culture, Deal and Peterson [49, p.1] note that "highly respected organizations have evolved a shared system of informal folkways and traditions that infuse work with meaning, passion and purpose" (p.1). They also observe that "cultural patterns are highly enduring, have a powerful impact on performance, and shape the ways people think, act, and feel" $[49$, p.4]. A setting in which teachers and educational leaders work as colleagues, and one in which every teacher grows, takes time to be forged [50]. Creating such an environment requires vision, energy and tenacity on the part of leaders. The challenge will be to sustain the 'fire' and keep the 'flame' alive.

\section{The Role of the Head of School}

A number of studies have highlighted the central role of the Head of School in determining the success or otherwise of reform $[40,51,52]$. In particular the studies stress the importance for the head to act as an educational leader and championing the reform process $[52,53]$.

Most Senior Management Teams (SMTs) indicated that they view the decentralising process and the allocation of greater autonomy in schools in a positive light [51, 52]. However, they lamented a considerable increase in workload. In particular they all profess that they consider themselves as educational leaders and shun the management role. Heads of School also reported that most of the time on task is utilised in the administrative role [40,51].

This point has been collaborated by a survey carried out by the education authorities [54] which highlights a number of concerns. The majority of respondents $(60 \%)$ noted that, up to now, College initiatives are not allowing the SMTs to focus on teacher support. Another $62 \%$ noted that they are not able to focus on teaching and learning. At the same time, $64 \%$ of the respondents note that inter-school support between SMTs has actually improved. This is collaborated by $60 \%$ of the respondents stating that shared decision making and distributed forms of leadership are empowering SMTs.

The study [54] notes that the impact of the reform on nurturing autonomy at the school level and for schools to undertake their own initiatives is still weak, and that College impact on the teaching and learning process is still negligible. If we acknowledge that reform takes place, as Fullan [37] notes, at a slow pace then we need to accept the collective responsibility to bring about change. This is the area that the following section addresses.

\section{Challenges}

One of the major challenges that the College Principals have to grapple with is the unavoidable complexity of building collective autonomy as against a prescriptive approach to change and development. We can see that people are at different levels of readiness for change. Everyone must contribute to create the conditions for change: this is being experienced as Colleges adopt a more strategic approach in planning change. Change, as a process, as something that is experienced on a day-to-day basis, shows the importance of studying and evaluating how change is implemented.

The toughest challenge will be how to sustain change through the work done within the Directorates and how they support the Colleges and schools sustain their own priorities and plans [30]. Sustaining change is rather difficult since it demands an unfailing commitment by one and all. Establishing and maintaining a competent system requires fundamental shifts in the way we view schools, the way we view learning and the way we conceptualize community.

The varied initiatives currently being introduced in the Maltese schools [14] go a long way to show that networks can assist in the "process of re-structuring and re-culturing educational organizations and systems" [31, p.5]. The examples $[42,44]$ shared are helping us to see a shift from unconnected thinking to systems thinking; from individuals working in isolation to one of collegiality; from acting on the basis of one's own interest or parochial vision to acting consistently to the interest of a shared vision, that is from individual autonomy to collective autonomy, and from individual accountability to collective accountability [50]. At the same time, the examples $[40,54]$ shared help us to appreciate that new concerns may be arising as people engage or disengage.

\section{Development Planning}

In education, whether at systems level or school level, we are slowly but surely getting to grips with the importance behind development planning, that is being regarded as an essential component behind change and development. Plans are made for action - the right or desired action. The purpose of planning is therefore to initiate an act that has the maximum probability of optimal results over a given period of time. Planning is directive and not restrictive. Within this 
context the challenge is one of sustainability, of sustaining change over time. We believe that any call to change is also a call to learn. To sustain education reforms we cannot rush through the implementation without giving ourselves time for reflection, for engagement, for testing things out $[55,56]$. Another aspect behind sustainability is the issue of endurance. If we are looking for continuity, leadership is no longer the prerogative of the few but must be distributed to the many. Our goal is not to find a charismatic individual who can do all things well and wisely, but to discover ways of sustaining productive change in our schools. Sustainable leadership means distributing the leadership throughout the College/School communities. In a highly complex world, no one leader, institution or nation can control everything without help [37]. Sustainable leadership must be a shared responsibility. Naturally there is a lot that needs to be unravelled, experienced, learnt as we navigate through the rapids of change. Whether at systems level or at College level we need to work together to not only manage change but pursue and model sustainable development. As Hargreaves and Fink [55] argue, leaders develop sustainability by committing to and protecting deep learning in their schools; by trying to ensure that improvements last over time, especially after they have gone; by distributing leadership and responsibility to others; by considering the impact of their leadership on the schools and communities around them; by sustaining themselves so that they can persist with their vision and avoid burning out; by promoting and perpetuating diverse approaches to reform rather than standardized prescriptions for teaching and learning; and by engaging actively with their environments.

\section{WHAT HAVE WE LEARNT SO FAR?}

Reform is all about embarking on a never ending journey, but one that is spearheaded by a vision of a better future. Whilst this may sound romantic we do believe that unless we have a clear vision of where we want to go than it is next to impossible to chart one's way forward. The decision to go towards a school network system and with it a more decentralized system of policy making and decision making has led to the creation of new opportunities and new challenges.

The study reported in this article has brought out a number of interesting points. First, change requires hard work and commitment. This is something that we have learnt from both our direct and indirect experiences. The reform process, that would surely be of interest to policy makers, needs school leaders to be more involved in the process of change and in sustaining commitment so as to ensure that a number of principles and practices are institutionalised. Whilst one has to bear in mind contextual factors what we are sharing, in our opinion, can cut across boundaries.

Second, at the heart of the reform are people and it is essential for the education authorities to adequately prepare personnel at all levels to handle shared and distributed forms of leadership. Some evidence shows that this is successfully being implemented whilst others are facing difficulties. Devolving responsibilities may not be easy especially in a context that has been used to a centralized system of control. A system of ongoing Directorate/College and school-based support is needed. We also encourage Continuing
Professional Development sessions that sees education officials at both Directorate and College level engaged to tackle issues of direct relevance. Such situations provides people with opportunities to learn to appreciate each other; to learn from each other; challenge existing habits and practices, and learn what distributed forms of leadership imply as they engage. Only through such efforts are people able to overcome the often isolationist, selfish and selfcentred approach to doing things that is embedded in our culture. In this way we will look forward and ensure that sustainability becomes part and parcel of our life.

Third, we feel that there is the need to create monitoring systems at all levels that allows members of staff to review practices as they unfold. This implies that educators in general need to adopt a culture of self-reflection and collaborative dialogue.

Finally, we are also ensuring that research, especially locally undertaken research, influences our policies. Over the past few years we are recognising the importance of undertaking research with the purpose of understanding the local context and spearheading reforms based on such findings. This research base is important even as the reform unfolds. In fact, this article itself is based on research in progress.

We hope that such points can help others in similar situations as they too grapple with the complexities of change.

\section{CONCLUSION}

Most leaders want to accomplish goals that matter, inspire others to join them in working toward those goals, and leave a legacy after they have gone. Leaders do not usually let their schools down; the failure often rests with the systems in which they lead. The results of our study indicate that sustainable leadership cannot be left to individuals, however talented or dedicated they are. If we want change to matter, to spread, and to last, then the systems in which leaders do their work must make sustainability a priority, hence creating opportunities for shared and distributed forms of leadership.

It is with this consideration in mind that we feel that such a reform needs to have embedded within the educational system a culture of Continuing Professional Development and a system of evaluation and review which are carried out within the Colleges themselves and from outside through the Quality Assurance Department, together with the support of researchers from within the Directorates and the Faculty of Education. We are of the opinion that such interventions will allow for different forms of learning to take place that allows the varied stakeholders to benefit from the findings of research work undertaken. Such research would help to identify issues of concern, areas for development that can help the reform process to have the desired impact where it matters. At the same time, opportunities for growth, through a College-based approach and a whole-systems approach would help people to develop their leadership skills as they address issues together.

\section{ACKNOWLEDGEMENT}

Declared none. 


\section{CONFLICT OF INTEREST}

The authors confirm that this article content has no conflict of interest.

\section{REFERENCES}

[1] James, CR, Balarin M, Brammer S, McCormack M. The school governance study. A research study commissioned by Business in the Community. London: CSR 2008.

[2] (a) Rhodes RAW. Understanding governance. Buckingham: Open University Press 1997; (b) Ouston J. Introduction, leadership, governance and community. In: Davies B, West Burnham J, Eds. Handbook of educational leadership management. London: Pearson 2003; pp. 225-7.

[3] Macnamara D. Models of corporate/board governance leadership acumen, Issue 21 - April/May 2005: 1-10, [On-line] .Available from: www.banffexeclead.com/Newsletter04/PDF/Leadership $\% 20$ Acumen\%2021\%20V2 [Retrieved: 2009, March 16].

[4] Ranson S. The changing governance in education. Educ Manag Admin Leadersh 2008; 37(4): 473-96.

[5] Stoker G. Governance as theory: five propositions'. Int Soc Sci J 1998; 50(155): 17-28.

[6] Ackerman J. Co-governance for accountability: beyond 'exit' and 'voice'. World Dev 2004; 32(3): 447-63.

[7] European Commission, European Governance website. Available at: http://ec.europa.eu/governance/governanceeu/indexen.htm) [Accessed June 2008].

[8] Carver J. Boards that make a difference: a new design for leadership in nonprofit and public organizations. San Francisco: Jossey-Bass 1997.

[9] Austen S, Swepson P, Marchant T. Governance and school boards in non-state schools in Australia. Manag Educ 2012; 26(2): 73-81.

[10] Lawn M, Ozga J. The sleep of reason breeds monsters: data and education governance in England. CES, Briefing Number 52, Edinburgh, Centre for Educational Sociology, University of Edinburgh 2009.

[11] Cowie M, Cisneros-Cohernour JE. Accountability and inclusion in Mexico and Scotland: how can principals act in principled ways. Int Stud Educ Admin 2011; 39(1): 103-17.

[12] Glatter R. Governance and educational innovation. In: Davies B, West-Burnham J, Eds. Handbook of educational leadership and management. London: Pearson 2003; pp. 228-37.

[13] O'Neill O. Lecture 3 entitled called to account from the series Reith lectures 2002: a question of trust. Available from: www.bbc.co.uk/radio4/reith2002/ [Retrieved 2011 August 3].

[14] Fabri F, Bezzina C, Eds. School improvement through school networks: the Malta experience. Malta: Ministry of Education, Employment and the Family 2010.

[15] Cutajar M. The nature of Collaborative Practice in a policy context for Maltese State Colleges. The MSEAM Seminar: Challenges, Opportunities, Discoveries - Quests in Educational Leadership and Beyond; 2011, 26 ${ }^{\text {th }}$ May; St. Julians, Malta.

[16] Caldwell B. School-based Management. Paris: International institute of educational planning series 2005.

[17] Wallace RC Jr. From vision to practice - the art of educational leadership. California: Corwin Press 1996.

[18] Gaziel H. Site-based management: emergence and effects: the case for Israel. Educ Admin Manag 2008; 36(3): 19-34.

[19] Kjaer AM. Governance. New Jersey: John Wiley \& Sons 2004

[20] James C, Brammer S, Fertig M. International perspectives on school governing under Pressure. Editorial. Educ Manag Admin Leadersh 2011; 39(4): 394-7.

[21] Riley K, MacBeath J. Effective leaders and effective schools. In: Macbeath J, (ed.) Effective School Leadership: responding to change. London: SAGE 1998.

[22] Weindling D, Earley P. Secondary Headship: The First Years. Nelson: NFER 1987.

[23] Thomas H, Martin J. Managing resources for School Improvement: creating a cost effective school. London: Routledge 1996.

[24] Stoll L, Fink D. Changing our Schools, $13^{\text {th }}$ ed. Maidenhead: Open University Press 2003.

[25] Bush T, Middlewood D. Managing People in Education. London: Paul Chapman 2006.

[26] Ranson S, Arnott M, McKeown P, Martin J, Smith P. The participation of volunteer citizens in school governance. Educ Rev 2005; 57(3): 357-71.
[27] Laws of Malta. Education Act (Act 24 of 1988). Department of Information: Valletta 1988.

[28] Fenech J. Education Policy and School Autonomy. In: Farrugia C, Ed. A New Vision for Primary Schools. MUT: Malta 1994.

[29] Wain K, Attard P, Bezzina C, et al. Tomorrow's Schools: developing effective learning cultures. Malta: Ministry of Education and Human Resources 1995.

[30] Ministry of Education, Youth and Employment Creating our Future Together - national minimum curriculum. Malta: Klabb Kotba Maltin 2001

[31] Ministry of Education, Youth and Employment. For all children to succeed: a new network organization for quality education in Malta. Malta: Ministry of Education 2005.

[32] Hammer M, Stanton SA. The reengineering revolution: a handbook. NY: HarperCollins 1995.

[33] Bezzina C. Improving the quality of schooling in Malta. Int J Educ Manag 1991; 5(4): 14-8.

[34] Bezzina C. A case for quality assurance: an internal and external prerogative for development in Malta. In: Bezzina $\mathrm{C}, \mathrm{Ed}$. Educational Leadership: nurturing meaning in a context of change. Directorate for Quality and Standards in Education Malta 2009.

[35] Laws of Malta. An Act to amend the Education Act, Cap. 327, known as 'Education (Amendment) Act, 2006, Department of Information, Valletta 2005.

[36] Bezzina C. Networks for nurturing professional learning communities. In: EXCEL Network National Conference Learning through Peer Collaboration. $17^{\text {th }}$ May 2005, Malta.

[37] Fullan M. The new meaning of educational change. $4^{\text {th }}$ ed. New York: Teachers College Press/ London: Routledge 2007.

[38] Hoerr TR. The Art of School Leadership. Alexandria, VA: Association for Supervision and Curriculum Development 2005.

[39] Fabri F. Educational Leadership in Malta: training and development needs in school networks. [EdD dissertation]. Institute of Education, University of London 2009.

[40] Grech A, Mifsud I. The changing role of the headteacher: impact of the college principal on headteacher in leading secondary schools in Malta. [M.Ed. (Educational Leadership) dissertation]. Faculty of Education, University of Malta 2008.

[41] Cutajar M. Educational reform in the Maltese Islands. Malta Rev Educ Res 2007; 5(1): 3-21.

[42] Caruana H. The vision of a college principal. In: Fabri F, Bezzina C, Eds. School improvement through school networks: The Malta experience. Ministry of Education, Employment and the Family, Malta 2010; pp. 65-9.

[43] Balzan S. Teacher leadership through learning communities: effects on professional growth through collaborative practice. $1^{\text {st }}$ International conference on educational leadership, educational leadership: nurturing meaning in a context of change, 2008 November 12-14, New Dolmen Hotel Malta.

[44] Gatt F. A community college where each diversity is treasured and celebrated. In: Fabri F, Bezzina C. Eds. School Improvement through School Networks: The Malta Experience. Malta: Ministry of Education, Employment and the Family 2010; pp. 71-88.

[45] Cutajar M. The nature of inter-school networking in the Maltese islands: a case study. The BELMAS annual conference, new organizations, new leadership; 2010 July 9-11; reading England.

[46] Barth R. Improving schools from within: Teachers, parents, and principals can make the difference. San Francisco: Jossey - Bass 1990.

[47] Sterrett W. Insights into action - successful school leaders share what works. Alexandria VA: ASCD 2011

[48] Houston PD, Blankstein AM, Cole RW, Eds. Out-of-the-Box Leadership. Thousand Oaks, CA: Corwin Press 2009.

[49] Deal T, Peterson K. Shaping school culture: The heart of leadership. San Francisco: Jossey - Bass 2003.

[50] Bezzina C. The road less travelled: Professional communities in secondary schools. Theory Pract 2006; 45(2): 159-67.

[51] Cachia S. Implementing Malta's new national minimum curriculum: Managing change in Maltese state secondary schools. [Masters dissertation]. Sheffield University England 2003.

[52] Camilleri J. Education reform in Maltese schools: Managing the implementation of education reform in a new Maltese college. [Masters dissertation] Faculty of Education, University of Malta 2008.

[53] Attard TM. CPD practice in Malta: The role of school leaders. The $1^{\text {st }}$ international conference on educational leadership, educational 
leadership: nurturing meaning in a context of change; 2008 November 12-14; New Dolmen Hotel Malta.

[54] Spiteri A. A meta analysis of the college network system in Malta. Quality Assurance Department, Directorate for Quality and Standards in Education Malta 2010.
[55] Hargreaves A, Fink D. The seven principles of sustainable leadership. Educ Leadersh 2004; 61(7): 8-13.

[56] Bezzina C. Towards the learning community: a Maltese experience. New Zealand educational administration and leadership society biennial conference, leaders make a difference; $200618^{\text {th }}-21^{\text {st }}$ April, Rutherford Hotel, Nelson, New Zealand.

(C) Bezzina and Cutajar; Licensee Bentham Open.

This is an open access article licensed under the terms of the Creative Commons Attribution Non-Commercial License (http://creativecommons.org/licenses/by-nc/3.0/) which permits unrestricted, non-commercial use, distribution and reproduction in any medium, provided the work is properly cited. 